\title{
LETTERS
}

\section{Saliva cotinine levels in users of electronic cigarettes}

\section{To the Editors:}

Electronic nicotine delivery systems (ENDS or electronic cigarettes) look like cigarettes but do not contain or burn tobacco. Instead, they comprise a battery-powered atomiser that produces a vapour for inhalation from cartridges containing humectants (propylene glycol or glycerol), flavours (e.g. tobacco, mint or fruit) and nicotine. Many smokers report using ENDS to quit smoking or to substitute for tobacco in smoke-free places [1, 2].

ENDS do attenuate craving for tobacco, but appear to deliver little nicotine to the blood $[3,4]$. Two studies have evaluated nicotine administration with different ENDS brands in ENDSnaïve smokers $[3,4]$. In one study, 32 smokers completed two 10-puff "vaping" bouts or smoked a cigarette [3]. In contrast to tobacco cigarettes, ENDS did not increase plasma nicotine reliably (plasma nicotine: $1.4 \mathrm{ng} \cdot \mathrm{mL}^{-1}$ and $0.5 \mathrm{ng} \cdot \mathrm{mL}^{-1}$, respectively, for two ENDS brands). In the other study, smokers used ENDS with a 16-mg nicotine cartridge for $5 \mathrm{~min}$, a nicotine inhaler for $20 \mathrm{~min}$ or their usual cigarette for $5 \mathrm{~min}$ [4]. Nicotine concentration in plasma, measured after $60 \mathrm{~min}$, was $1.3 \mathrm{ng} \cdot \mathrm{mL}^{-1}$ for ENDS, $2.1 \mathrm{ng} \cdot \mathrm{mL}^{-1}$ for inhalers and $13.4 \mathrm{ng} \cdot \mathrm{mL}^{-1}$ for tobacco cigarettes, but one-third of participants showed no increase in blood nicotine while using the ENDS [4]. The time to maximum concentration of serum nicotine was shorter for ENDS (19.6 min) than for the nicotine inhaler (32.0 min), suggesting some absorption via the respiratory tract [4]. It is possible that serum nicotine levels would have been similar in ENDS and inhaler users, had ENDS users been allowed to use the devices for $20 \mathrm{~min}$ as for the inhaler.

However, regular ENDS users may draw 120-175 puffs $\cdot$ day $^{-1}$ on average $[1,2]$, which is substantially more than the exposure levels used in these laboratory studies. To date, nicotine or cotinine (a metabolite of nicotine) have not been measured in experienced ENDS users. The assessment of whether ENDS actually deliver nicotine to users is crucial for regulation, for abuse liability assessment and to indicate whether ENDS have potential as smoking cessation aids. We therefore sought to measure cotinine in the saliva of experienced ENDS users contacted in real-life settings.

Because ENDS are purchased mainly on the internet [1, 2], we posted a questionnaire in English and French on the smoking cessation website Stop-Tabac.ch between September 2010 and January 2011. We asked discussion forums and websites informing about ENDS or selling them to publish links to the survey (http://www.stop-tabac.ch/fr_hon/ECIG_EN). The online questionnaire covered ENDS use (current/past and duration), smoking status, age, sex and postal address. Current ENDS users were sent by mail a plastic vial, a consent form and an additional questionnaire on paper, which covered ENDS use (days per week), brand and model, whether their current ENDS contained nicotine, nicotine dosage, puffs $\cdot$ day $^{-1}$, refills $\cdot$ day $^{-1}$, tobacco cigarettes per day (in smokers), quit date (in ex-smokers) and any tobacco, nicotine replacement therapy (NRT) and ENDS use in the previous $48 \mathrm{~h}$. Participants were aged $>18$ yrs and the study was approved by the ethics committee of the Geneva University Hospitals (Geneva, Switzerland).

Participants were instructed to collect the saliva samples no less than $30 \mathrm{~min}$ after eating or drinking, using the provided plastic vial which contained a small cotton roll similar to those used by dentists (Salivette; Sarstedt, Nümbrecht, Germany). They were asked to chew the cotton roll for $1 \mathrm{~min}$ then replace it in the vial and return it to us by mail. Upon receipt, vials were stored at $-4^{\circ} \mathrm{C}$ for a few days and then shipped by express mail to ABS Laboratories (Welwyn Garden City, UK) for cotinine analysis by gas chromatography.

We posted vials to the 196 current ENDS users and received 31 vials back (a $16 \%$ response rate). The median age of the 31 participants was 41 yrs and most $(65 \%)$ were males. The distribution of respondents by country was: USA $(n=18)$, France $(\mathrm{n}=4)$, UK $(\mathrm{n}=4)$, Switzerland $(\mathrm{n}=3)$, Canada and Italy $(\mathrm{n}=1$ each). Most participants (30 out of 31, 97\%) were former smokers who had not smoked in the previous $48 \mathrm{~h}$. There was one occasional smoker who was currently trying to quit and smoked one cigarette day $^{-1}$. Former smokers had been abstinent for a median 4.2 months (25th and 75th percentiles: 49 days and 10.5 months, range 20 days-2 yrs). No participant reported using NRT or smokeless tobacco in the $48 \mathrm{~h}$ prior to saliva collection.

All participants but one used ENDS daily. Participants puffed a median of 200 times $^{-d_{a y}{ }^{-1}}$ on their ENDS (25th and 75th percentiles: 100 and 400 puffs $\cdot$ day $^{-1}$, range 50-1,000 puffs $^{-}$day $^{-1}$, mean \pm SD $250 \pm 205$ puffs $\cdot$ day $\left.^{-1}\right)$. The most used brands were Joye $(n=9,29 \%)$ and Janty $(n=4,13 \%)$, and the most used models, sold under different brand names, were Ego $(n=12,39 \%)$ and 510 $(n=7,23 \%)$. On average, the concentration of nicotine in refill liquids was $18 \mathrm{mg} \cdot \mathrm{mL}^{-1}$, and participants used five refills or cartridges per day. At the time of saliva collection, participants had been using ENDS for a median of 94 days (25th and 75th percentiles: 45 days and 10 months, range 16 days $-3 \mathrm{yrs}$ ).

In the 30 ENDS users who, in the previous $48 \mathrm{~h}$, had not used tobacco or NRT but had used ENDS, median cotinine level was $322 \mathrm{ng} \cdot \mathrm{mL}^{-1}$ (25th and 75th percentiles: 138 and $546 \mathrm{ng} \cdot \mathrm{mL}^{-1}$, range $13-852 \mathrm{ng} \cdot \mathrm{mL}^{-1}$, mean $\pm \mathrm{SD} 338 \pm 227 \mathrm{ng} \cdot \mathrm{mL}^{-1}$ ), and correlation between cotinine and puffs $\cdot$ day $^{-1}$ on ENDS was $r=0.39$ ( $15 \%$ of variance explained, $\mathrm{p}=0.034)$. The only smoker drew 150 puffs $\cdot$ day $^{-1}$ on his ENDS and had $141 \mathrm{ng} \cdot \mathrm{mL}^{-1}$ cotinine. The only non-daily user used ENDS on 2 days $\cdot$ week $^{-1}$ and had $13 \mathrm{ng} \cdot \mathrm{mL}^{-1}$ cotinine.

We found substantial amounts of cotinine in the saliva of ENDS users. These results contrast with two laboratory reports 
that concluded that ENDS did not reliably increase blood nicotine levels [3], or provided lower levels than nicotine inhalers or tobacco cigarettes [4]. The differences with our study may be explained by different durations of exposure, users' experience with the devices, puffing characteristics, models used and the swallowing of nicotine. In our study, experienced users puffed intensively and had been using ENDS regularly for months, whereas the previous studies were conducted in ENDS-naïve users. Experience with the device is likely to have influenced blood nicotine/cotinine levels. The correlation between puff number and cotinine suggests that puffing topography is an important factor that should be controlled for in future studies. Furthermore, in our study, participants used some of the most popular brands and models identified in user surveys [1, 2], whereas those tested in previous studies may be less popular, and it is possible that the models used in this study delivered more nicotine than those previously tested. ENDS users may swallow some of the nicotine, thus removing it from the circulation and submitting it to first-pass metabolism in the liver. Thus, it may be difficult to compare studies that assess nicotine with those that assess cotinine, and it may also be difficult to compare cotinine levels in ENDS users, nicotine patch users and smokers. However, a substantial part of the nicotine in oral forms of NRT is also swallowed [5].

Nevertheless, cotinine levels in ENDS users were similar to levels previously observed in smokers [6] and higher than levels previously found in NRT users $[7,8]$. Cotinine levels are roughly similar when measured in blood or in saliva $[6,9,10]$, so studies using cotinine in blood and in saliva can be compared. Participants had not smoked for $\geqslant 20$ days and had not used NRT or smokeless tobacco for $\geqslant 48 \mathrm{~h}$ (about three times the half-life of cotinine in smokers) [10]. Thus, results are unlikely to be contaminated by other sources of nicotine. All participants but one were former smokers, suggesting that ENDS are used much like NRT, to assist quitting, with similar or even larger effects on nicotine exposure. In this light, it seems logical to apply the same evaluation requirements to ENDS as to NRT. Even though propylene glycol is authorised as an additive in foods and medications, the effects of repeatedly inhaling a vapour containing propylene glycol over long periods are unknown.

We relied on a self-selected sample and on self-reports of use of ENDS, tobacco and NRT, with no objective verification. Thus, our results may have limited generalisability and should be interpreted with caution. Nevertheless, this study shows that large amounts of nicotine can be obtained from ENDS and this calls for confirmation in representative samples or with different methods. Finally, technology progresses rapidly, and our results may not apply to future ENDS models.

We conclude that cotinine levels in ENDS users were similar to levels observed, in previous reports, in smokers and higher than levels usually observed in NRT users. This finding has important implications for ENDS use by smokers who want to quit, for future research, and for the regulation of these products.

\section{J-F. Etter* and C. Bullen ${ }^{\#}$}

*Institute of Social and Preventive Medicine, Faculty of Medicine, University of Geneva, Geneva, Switzerland, and "Clinical Trials Research Unit, School of Population Health, University of Auckland, Auckland, New Zealand.

Correspondence: J-F. Etter, Institute of Social and Preventive Medicine, University of Geneva, CMU, Case Postale, CH-1211 Geneva 4, Switzerland. E-mail: Jean-Francois.Etter@unige.ch

Support Statement: No external funding was received for this study.

Statement of Interest: Statements of interest for both authors of this manuscript can be found at www.erj.ersjournals.com/ site/misc/statements.xhtml

Acknowledgements: V. Baujard (HON Foundation, Geneva, Switzerland; www.hon.ch) developed the software for data collection.

\section{REFERENCES}

1 Etter J-F. Electronic cigarettes: a survey of users. BMC Public Health 2010; 10: 231.

2 Etter J-F, Bullen C. Electronic cigarettes: users profile, utilization, satisfaction and perceived efficacy. Addiction 2011; [Epub ahead of print DOI: 10.1111/j.1360-0443.2011.03505.x].

3 Vansickel AR, Cobb CO, Weaver MF, et al. A clinical laboratory model for evaluating the acute effects of electronic "cigarettes": nicotine delivery profile and cardiovascular and subjective effects. Cancer Epidemiol Biomarkers Prev 2010; 19: 1945-1953.

4 Bullen C, McRobbie H, Thornley S, et al. Effect of an electronic nicotine delivery device (e cigarette) on desire to smoke and withdrawal, user preferences and nicotine delivery: randomised cross-over trial. Tobacco Control 2010; 19: 98-103.

5 Benowitz NL, Jacob P 3rd, Savanapridi C. Determinants of nicotine intake while chewing nicotine polacrilex gum. Clin Pharmacol Ther 1987; 41: 467-473.

6 Wall MA, Johnson J, Jacob P, et al. Cotinine in the serum, saliva, and urine of nonsmokers, passive smokers, and active smokers. Am J Public Health 1988; 78: 699-701.

7 Benowitz NL, Zevin S, Jacob P 3rd. Sources of variability in nicotine and cotinine levels with use of nicotine nasal spray, transdermal nicotine, and cigarette smoking. Br J Clin Pharmacol 1997; 43: 259-267.

8 Gourlay SG, Benowitz NL, Forbes A, et al. Determinants of plasma concentrations of nicotine and cotinine during cigarette smoking and transdermal nicotine treatment. Eur J Clin Pharmacol 1997; 51: 407-414.

9 Jarvis MJ, Tunstall-Pedoe H, Feyerabend C, et al. Comparison of tests used to distinguish smokers from nonsmokers. Am J Public Health 1987; 77: 1435-1438.

10 Machacek DA, Jiang NS. Quantification of cotinine in plasma and saliva by liquid chromatography. Clin Chem 1986; 32: 979-982. 